\title{
APPLICATION OF THE RULE OF MIXTURES AND HALPIN-TSAI EQUATIONS TO WOVEN FABRIC REINFORCED EPOXY COMPOSITES
}

\author{
M. Abdel Ghafaar ; A. A. Mazen \\ Design and Production Engineering Department, Faculty of Engineering, Minia \\ University, Minia, Egypt \\ N. A. El-Mahallawy \\ Production Engineering Department, Faculty of Engineering, Ain Shams University, \\ Cairo, Egypt
}

(Received October 16, 2005 Accepted December 7, 2005)

A mathematical analysis is conducted on the experimental results of a study conducted on epoxy-based glass fiber reinforced plastics (GFRP) composites. Three different types of reinforcements were used in the form of woven fibers. Fabrics made of glass fibers, carbon fibers, and (glass-carbon) hybrid fibers were used at different volume fractions.

The rule of mixtures (ROM) and the Hapin-Tsai $(H-T)$ equations were used to analyze the experimental results. It was found that the ROM equations give approximate upper bound values for all investigated composites, for all considered volume fractions.

It was also found that there is good agreement between $H$-T calculated values of fracture stress and those values that were determined experimentally for all volume fractions investigated.

Elastic modulus values calculated according to $H$-T equations showed good agreement with experimental values at low reinforcement volume fractions. However, as the volume fraction increased, the experimental and calculated values diverted from each other considerably.

A correlation function was calculated based on the differences between the elastic modulus values determined experimentally and those derived from $H$ - $T$ calculations. This function was applied to $H$-T values and thus, the differences between them and the experimental data were reduced.

KEYWORDS : Epoxy composites - woven fabric reinforcement - rule of mixtures Halpin-Tsai equations - fracture stress - elastic modulus.

\section{NOMENCLATURE}

$\mathrm{E}_{1} \quad$ Longitudinal moduls of elasticity of composites.

$\mathrm{E}_{\mathrm{f}} \quad$ Longitudinal moduls of elasticity of fibers.

$\mathrm{E}_{\mathrm{m}} \quad$ Longitudinal moduls of elasticity of matrix.

$\mathrm{E}_{\mathrm{hl}} \quad$ Longitudinal moduls of elasticity of hybrid interply composites. 
$\mathrm{E}_{\mathrm{g}} \quad$ Longitudinal moduls of elasticity of glass fibers.

$\mathrm{E}_{\mathrm{c}} \quad$ Longitudinal moduls of elasticity of carbon fibers.

$\mathrm{V}_{\mathrm{m}} \quad$ Volume fraction of matrix .

$V_{f} \quad$ Volume fraction of fibers .

$\mathrm{V}_{\mathrm{c}} \quad$ Volume fraction of carbon fibers .

$\sigma_{1} \quad$ Fracture stress of composites .

$\sigma_{\mathrm{f}} \quad$ Fracture stress of fibers .

$\sigma_{\mathrm{m}} \quad$ Fracture stress of matrix .

$\sigma_{\mathrm{hL}} \quad$ Fracture stress of hybrid interply composites .

$\sigma_{g} \quad$ Fracture stress of glass fibers.

$\sigma_{\mathrm{c}} \quad$ Fracture stress of carbon fibers .

\section{1- INTRODUCTION}

Composite materials are successfully replacing conventional metals in many applications. Light weight, high specific strength and stiffness, affordability, and ease of manufacturing are few of the advantages of composites over traditional metals. The wide-scale adoption of composite materials in many engineering applications necessitates a thorough understanding of the strength and mechanics of these materials. Many investigations have been conduced to suggest new equations or to develop existing equations, that describe the composite strength. Chamis and Sendeckyj [1] presented a summary and a review of the various methods and models used for obtaining composite properties. In order of complexity, these models can be listed as follows:

a- The mechanics of materials approach,

b- The self-consistent field method,

c- The variational calculus method, and,

d- The numerical techniques approach.

The mechanics of materials approach can be considered the simplest and easiest to apply. Several equations have been developed according to this approach. The most widely used ones are : the rule of mixtures (ROM), and Halpin-Tsai (H-T) equations. The basic assumptions used for the development of (ROM) and (H-T) equations, as well as most micromechanical approach are: both matrix and fibers are linearly elastic, isotropic, and homogeneous, fibers are perfectly aligned and spaced, matrix is void free, and bonding between matrix and fibers is perfect.

According to ROM, two moduli of elasticity can be derived, $\mathrm{E}_{1}$, and $\mathrm{E}_{2}$. Directions 1 and 2 represent loading directions aligned to and perpendicular to fiber directions, Fig. 1

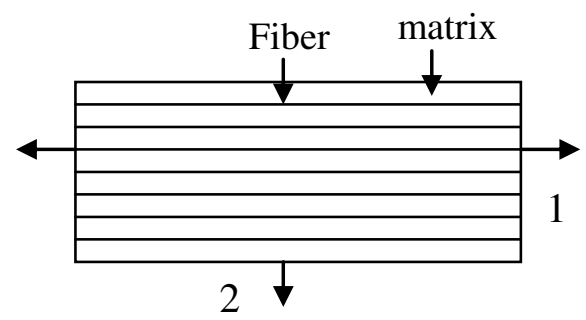

Fig. 1 
The first modulus, E1, is given by [2] :

$$
\mathrm{E}_{1}=\mathrm{E}_{\mathrm{f}} \mathrm{V}_{\mathrm{f}}+\mathrm{E}_{\mathrm{m}} \mathrm{V}_{\mathrm{m}}
$$

The strength of a unidirectional composite, $\sigma_{c}$, can be obtained according to the ROM from the equation.

$$
\sigma_{\mathrm{c}}=\sigma_{\mathrm{f}} \mathrm{V}_{\mathrm{f}}+\sigma_{\mathrm{m}}\left(1-\mathrm{V}_{\mathrm{f}}\right)
$$

These equations are based on the assumption of isostrain,

i.e. $\quad \varepsilon_{\mathrm{c}}=\varepsilon_{\mathrm{f}}=\varepsilon_{\mathrm{m}}$

This assumption is represented by springs-in-parallel model.

Equation (1) assumes no interaction between fibers and matrix. Thus, each constituent contributes its full capacity to the strength of the composite. Therefore, it gives an upper bound for composite strength.

The second modulus, $\mathrm{E}_{2}$, according to the ROM, is given for transverse loading, i.e. load is applied perpendicular to fiber direction. Derivation of $E_{2}$ assumes isostress, i.e.:

$$
\sigma_{\mathrm{c}}=\sigma_{\mathrm{f}}=\sigma_{\mathrm{m}}
$$

However, no plausible assumption or explanation is mentioned regarding the relationship between the strains in the fibers and in the matrix in the 2-direction. Modulus $\mathrm{E}_{2}$ is given by [2]:

$$
\mathrm{E}_{2}=\frac{E_{f} E_{m}}{V_{m} E_{f}+V_{f} E_{m}}
$$

A simple springs-in-series model represents the representative volume element loaded in the 2- direction. Comparing predictions from equation (3) to experimental data shows that equation (3) gives a lower bound for composite strength [3].

The ROM can also be used to evaluate the properties of composites reinforced by hybrid reinforcements that consist of two different fibers. In this case, another assumption is made in the derivation of the equations, i.e. that the longitudinal modulus of elasticity of the polymeric matrix is very small compared to that of the two types of fibers [4]. Thus, the elastic modulus, and the fracture strength of the composite are obtained from :

$$
\begin{aligned}
& E_{h l}=E_{g}\left(1-V_{m}\right)+\left(E_{c}-E_{g}\right) V_{c} \\
& \sigma_{h l}=\sigma_{g}\left(1-V_{m}\right)+\left(\sigma_{c}-\sigma_{g}\right) V_{c}
\end{aligned}
$$

Halpin and Tsai [5] developed empirical generalized equations that readily give quite satisfactory approximation of more complicated micromechanics results. These equations are quite accurate at low fiber volume fraction. They are also useful in determining the properties of composites that contain discontinuous fibers oriented in the loading direction [6].

The Halpin- Tsai (H-T) equations can be written as :

$$
\mathrm{M} / \mathrm{M}_{\mathrm{m}}=\left(1+\xi \eta \mathrm{V}_{\mathrm{f}}\right) /\left(1-\eta \mathrm{V}_{\mathrm{f}}\right)
$$

Where 


$$
\eta=\frac{\left(M_{f} / M_{m)}\right)-1}{\left(M_{f} / M_{m}\right)+\xi}
$$

Where $M$ represents composite moduli, e.g. $E_{11}, E_{22}, G_{12}, G_{23}, V_{12}, V_{23}$, etc., $M_{f}$ and $M_{m}$ represent corresponding fiber and matrix moduli, respectively. $\mathrm{V}_{\mathrm{f}}$ is the fiber volume fraction, and $\xi$ is a measure of reinforcement of the composite material that depends on the fiber geometry, packing geometry and loading conditions. The term $\xi$ is an empirical factor that is used to make equation (6) conforms to the experimental data. The function $\eta$ in equation (7) is constructed in such a way that when $V_{f}=0, M=M_{m}$, and when $\mathrm{V}_{\mathrm{f}}=1, \mathrm{M}=\mathrm{M}_{\mathrm{f}}$. So, for $\xi \rightarrow 0$ :

$$
\begin{aligned}
& \qquad \frac{1}{M}=\frac{V_{m}}{M_{m}}+\frac{V_{f}}{M_{f}} \\
& \text { and for } \xi \rightarrow \infty: \mathrm{M}=\mathrm{M}_{\mathrm{f}} \mathrm{V}_{\mathrm{f}}+\mathrm{M}_{\mathrm{m}} \mathrm{V}_{\mathrm{m}}
\end{aligned}
$$

These two extremes bound the composite properties. Equation (8) gives a lower bound, while equation (9) which is the well-known rule of mixtures equation gives an upper bound.

Whitney [7] suggests $\xi=1$ or 2 for the transverse modulus $E_{22}$ depending on the fiber array type, e.g. hexagonal, square, etc. Nielsen [8], modified the H-T equations to include the maximum packing factor $\phi_{\max }$ of reinforcement.

The goal of the present work is to investigate the applicability of the rule of mixtures and the Halpin-Tsai equations to the results of an experimental study conducted by the present authors. Three different composites were investigated ; epoxy reinforced by glass fibers $\left(\mathrm{V}_{\mathrm{f}}=9.2\right.$ up to 36.8 vol. \%), epoxy reinforced by carbon fibers $\left(\mathrm{V}_{\mathrm{f}}=\right.$ 36.8 vol. \%), and epoxy reinforced by hybrid fibers consisting of interlaminar layers of glass and carbon fabrics $\left(\mathrm{V}_{\mathrm{f}}=36.8\right.$ vol. $\left.\%\right)$.

\section{2- EXPERIMENTAL RESULTS}

An experimental study was conducted by the present authors [9] on epoxy matrix reinforced by woven fabrics. Tensile, compressive, and bending tests were used to evaluate the mechanical properties of the composites. Glass fibers, carbon fibers, and glass-carbon hybrid fibers were used in the woven form. The fiber volume fractions for woven glass reinforcement ranged from 9.2 vol. \% to 36.8 vol. \%. A 36.8 vol. \% reinforcement volume fraction was used for both carbon and hybrid (carbon/glass) woven fabrics.

\subsection{Material Properties}

Table 1 gives a summary of the data of the composite constituents. These data are provided by the supplier.

As mentioned earlier three different types of composites were investigated. All composites had an epoxy matrix. Three different types of reinforcements were used, e.g. woven glass fibers, woven carbon fibers, and hybrid (glass/carbon) interplay fibers. 
Table 1: Mechanical Properties of Composite Constituents.

\begin{tabular}{|l|c|}
\hline 1- Matrix : \\
\hline Elastic Modulus, $\mathrm{E}_{\mathrm{m}}$ & $2.66 \mathrm{GPa}$ \\
\hline Fracture Stress, $\sigma_{\mathrm{m}}$ & $57.20 \mathrm{MPa}$ \\
\hline 2- Woven Glass Fibers : & $72.00 \mathrm{GPa}$ \\
\hline Elastic Modulus, $\mathrm{E}_{\mathrm{g}}$ & $3.45 \mathrm{GPa}$ \\
\hline Fracture Stress, $\sigma_{\mathrm{g}}$ & \\
\hline 3- Woven Carbon Fibers : & $320.00 \mathrm{GPa}$ \\
\hline Elastic Modulus, $\mathrm{E}_{\mathrm{c}}$ & $3.53 \mathrm{GPa}$ \\
\hline Fracture Stress, $\sigma_{\mathrm{c}}$ &
\end{tabular}

\subsection{Composite Properties}

Table 2 gives a summary of the mechanical properties of the investigated composites under tensile loading.

Table 2a : Mean Values ${ }^{(*)}$ of Tensile Properties for GFRE.

\begin{tabular}{|c|c|c|c|c|}
\hline $\begin{array}{c}\text { Volume } \\
\text { fractions of } \\
\text { fibers }\end{array}$ & $\begin{array}{c}\text { Strain at } \\
\text { fracture } \\
\boldsymbol{\varepsilon}_{\mathbf{f}} \text { \% }\end{array}$ & $\begin{array}{c}\text { Fracture } \\
\text { stress } \mathbf{S}_{\mathbf{f}} \mathbf{M P a}\end{array}$ & $\begin{array}{c}\text { Modulus of } \\
\text { elasticity } \mathbf{E} \\
(\mathbf{G P a})\end{array}$ & $\begin{array}{c}\text { Modulus of } \\
\text { resilience } \\
\mathbf{U}_{\mathbf{r}(\mathbf{N} . \mathbf{m m} / \mathbf{m m}}\end{array}$ \\
\hline 0 & 1.475 & 46.29 & 2.66 & 0.34 \\
\hline $9.2 \%$ & 1.45 & 62.56 & 5.67 & 0.454 \\
\hline $18.4 \%$ & 1.52 & 74.7 & 7.8 & 0.57 \\
\hline $36.8 \%$ & 2.65 & 173.4 & 10.6 & 0.32 \\
\hline
\end{tabular}

* Average of at least three tests.

Table 2b: Mean Values ${ }^{(*)}$ of Tensile Properties of GFRE, Hybrid and CFRE.

\begin{tabular}{|c|c|c|c|c|c|}
\hline $\begin{array}{c}\text { Type of } \\
\text { Laminate }\end{array}$ & $\begin{array}{c}\text { Volume } \\
\text { fractions of } \\
\text { fibers }\end{array}$ & $\begin{array}{c}\text { Strain at } \\
\text { fracture } \\
\mathbf{\varepsilon}_{\mathbf{f}} \%\end{array}$ & $\begin{array}{c}\text { Fracture } \\
\text { stress } \mathbf{S}_{\mathbf{f}} \\
\mathbf{M P a}\end{array}$ & $\begin{array}{c}\text { Modulus of } \\
\text { elasticity } \mathbf{E} \\
(\mathbf{G P a})\end{array}$ & $\begin{array}{c}\text { Modulus of } \\
\text { resilience } \\
\mathbf{U}_{\mathbf{r}(\mathbf{N} . \mathbf{m m} / \mathbf{m m}}\end{array}$ \\
\hline GFRE & $36.8 \%$ & 2.65 & 173.4 & 10.6 & 2.3 \\
\hline Hybrid & $36.8 \%$ & 2.285 & 273.5 & 12.4 & 3.12 \\
\hline CFRE & $36.8 \%$ & 2.53 & 360.63 & 16.8 & 4.56 \\
\hline
\end{tabular}

$*$ Average of at least three tests.

\section{3- APPLICATION OF THE ROM EQUATIONS TO PRESENT STUDY}

The data given in Table 1 were used to calculate the elastic modulus and fracture strength of the different types of composites according to equations (2), (4), and (5). Figures 2 and 3 show plots of the experimentally determined modulus and fracture strength, versus the same parameters calculated using the ROM equations.

It is clear that there is a big difference between ROM calculated values for $\mathrm{E}$ and $\sigma_{\mathrm{f}}$, and the experimentally determined ones. The ROM calculated data gives higher values for all volume fractions of fibers investigated, and for all types of composites.

This shows that the ROM equations for calculation of properties of fiber reinforced epoxy and hybrid fiber reinforced epoxy give upper bound results. 


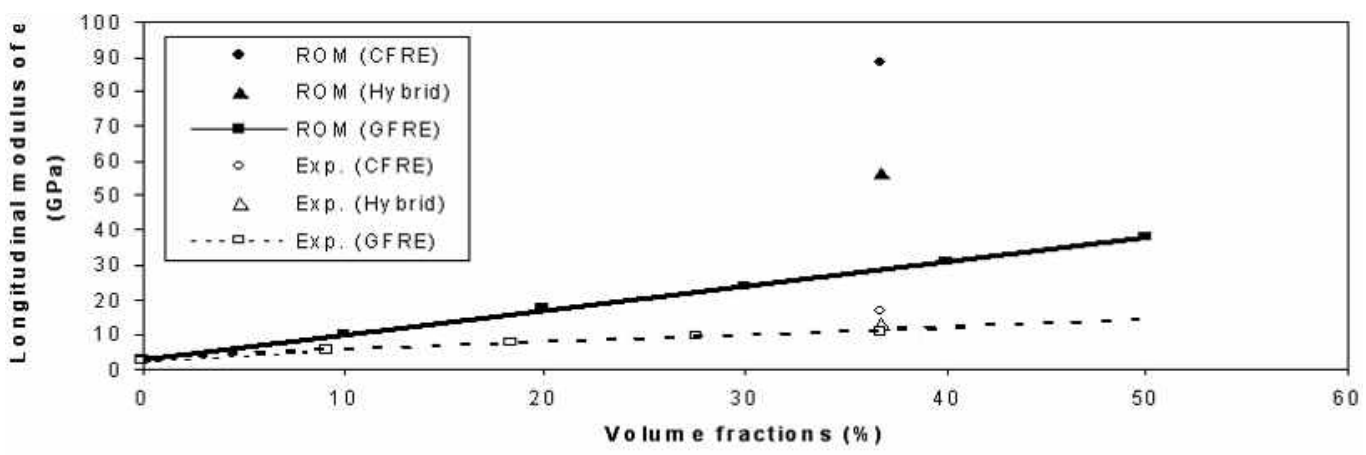

Fig. 2: Application of ROM to experimental data for elastic modulus.

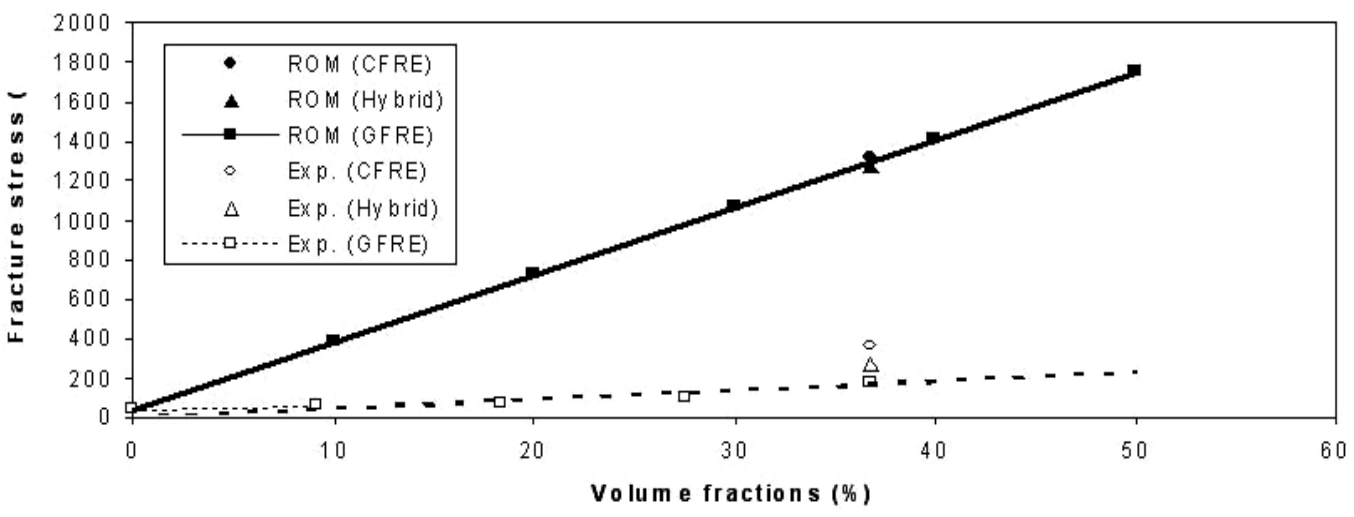

Fig. 3: Application of ROM to experimental data for fracture stress.

\section{4- APPLICATION OF HALPIN-TSAI EQUATIONS TO PRESENT STUDY}

Equations (6) and (7) were used to calculate the elastic modulus and the fracture stress of the composites reported in the present study. The parameters used were as follows : $\mathrm{E}_{\mathrm{m}}=2.66 \mathrm{GPa}, \sigma_{\mathrm{m}}=57.2 \mathrm{MPa}, \mathrm{E}_{\mathrm{g}}=72.0 \mathrm{GPa} \mathrm{E}_{\mathrm{Car}}=320 \mathrm{GPa}, \sigma_{\mathrm{car}}=3.53 \mathrm{GPa}$. Volume fractions varying from 9.2 vol. $\%$ to 36.8 vol. $\%$ were considered for glass fibers, while a single volume fraction of 36.8 vol. \% was considered for each of the carbon, and hybrid reinforcements. The empirical parameter $\xi$ was taken $=2.0$ according to reference [6] .

Figures 4 and 5 show plots of the data obtained experimentally and those calculated according to Halpin-Tasi equations.

It is clear that for low volume fractions of GFRP, there is good agreement between the date obtained experimentally and those calculated according to H-T equations. As the reinforcement volume fraction increases, noticeable divergence is observed for the data of the elastic modulus. However, the data of the fracture stress continue to show very good agreement up to the largest volume fractions of fibers investigated. 
Extrapolation of both the experimental and calculated fracture stress data show that H.T equations could be used satisfactorily to give accurate results . This can be seen in Fig. 5 by extrapolating the experimental data trend (the dashed line) and the calculated values curve (the solid line).

It can be concluded that the H-T equations need to be modified in regards to calculations of the elastic modulus.

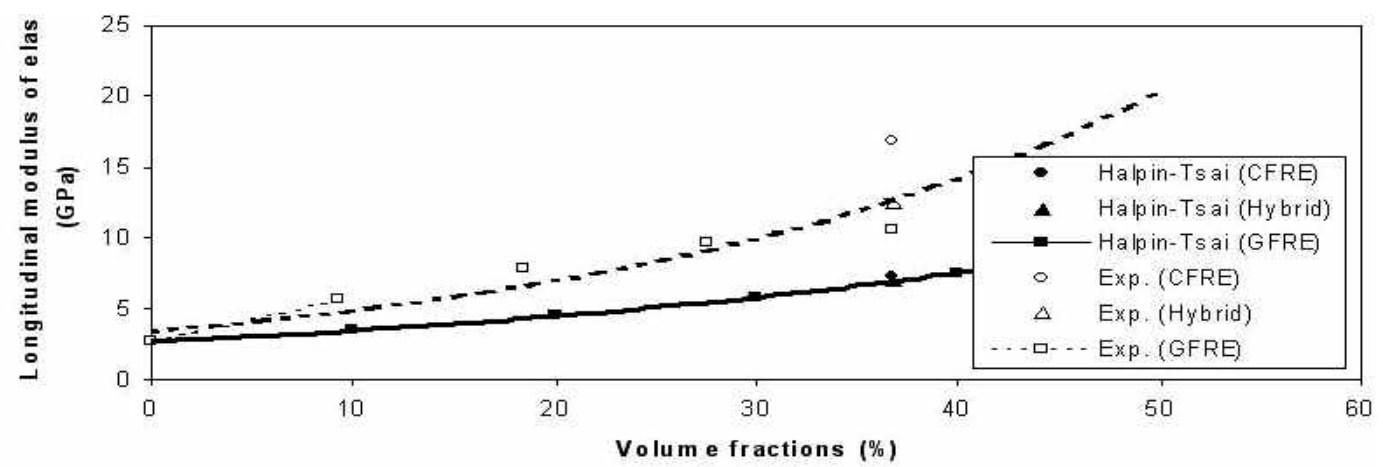

Fig. 4: Application of Halpin-Tsai equations to experimental data for the elastic modulus.

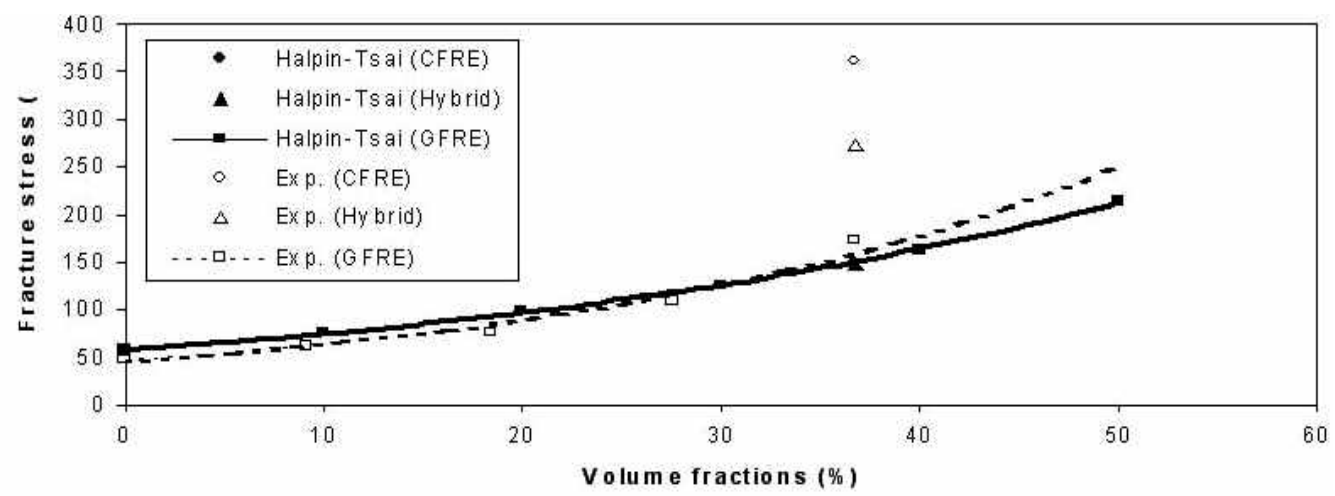

Fig. 5: Application of Halpin-Tsai equations to experimental data for the fracture stress.

\section{5- MODIFICATION OF THE H-T EQUATIONS}

As mentioned above, the H-T equations need to be modified in order to get good correlation between experimental and calculated elastic modulus data. The reinforcements investigated in the present study consist of woven fabrics. Woven fabrics could be considered as consisting of two separate types of fibers, i.e. longitudinal fibers, and transverse ones. Each of these constituents is $1 / 2 V_{f}$ (Where $V_{f}$ is the reinforcement volume fraction). Thus, the elastic modulus of the composite could be written as :

$$
\mathrm{E}_{\mathrm{c}}=\mathrm{E}_{1}+\mathrm{E}_{2}
$$


Where $E_{1}$ is the elastic modulus contribution due to longitudinal fibers, and $E_{2}$ is the contribution of the transverse fibers to the elastic modulus.

Imposing a correlation factor, $\mathrm{F}_{1}$, on equation (10), we may write :

$$
\mathrm{E}_{\mathrm{c}}=\mathrm{F}_{1}\left[\mathrm{E}_{1}+\mathrm{E}_{2}\right]
$$

$\mathrm{F}_{1}$ is a correlation function that depends primarily on the reinforcement volume fraction and type of fibers. It is expected that $F_{1}$ is strongly affected by other factors, e.g. fiber arrangement, bond strength between fibers and matrix, etc.

$\mathrm{F}_{1}$ is calculated to reduce the differences between the experimentally determined data and the calculated ones.

Halpin-Tsai equations can now be written as :

$$
\begin{aligned}
\mathrm{E}_{\mathrm{c}}= & \mathrm{F}_{1}\left[\mathrm{E}_{1}+\mathrm{E}_{2}\right] \\
= & \mathrm{F}_{1}\left\{\left[\mathrm{E}_{\mathrm{m}}\left(1+\xi_{\mathrm{L}} \eta_{\mathrm{L}} \mathrm{V}_{\mathrm{f}} / 2\right) /\left(1-\eta_{\mathrm{L}} \mathrm{V}_{\mathrm{f}} / 2\right)\right]+\right. \\
& {\left.\left[\mathrm{E}_{\mathrm{m}}\left(1+\xi_{\mathrm{t}} \eta_{\mathrm{t}} \mathrm{V}_{\mathrm{f}} / 2\right) /\left(1-\eta_{\mathrm{t}} \mathrm{V}_{\mathrm{f}} / 2\right)\right]\right\} }
\end{aligned}
$$

Where :

$\mathrm{E}_{\mathrm{c}} \quad$ is the elastic modulus of the composite loaded in the 1- direction,

$\mathrm{E}_{1} \quad$ is the contribution of the longitudinal fibers to $\mathrm{E}_{\mathrm{c}}$ the elastic modulus,

$\mathrm{E}_{2} \quad$ is the contribution of the transverse fibers to $\mathrm{E}_{\mathrm{c}}$,

$\mathrm{F}_{1} \quad$ is an empirical correlation function determined based on the differences between the experimental and calculated data,

$\eta_{\mathrm{L}}, \eta_{\mathrm{t}}$ calculated parameters based on

$$
\left.\xi_{\mathrm{L}} \text { and } \xi_{\mathrm{t}} \cdot\left[\eta=\left(\mathrm{M}_{\mathrm{f}} / \mathrm{M}_{\mathrm{m}}\right)-1\right]\left[\mathrm{M}_{\mathrm{f}} / \mathrm{M}_{\mathrm{m}}\right)+\xi\right]
$$

$\xi_{\mathrm{L}} \quad$ empirical parameter $=2$ for longitudinal direction,

$\xi_{\mathrm{t}} \quad$ empirical parameter $=0.5$ for transverse direction

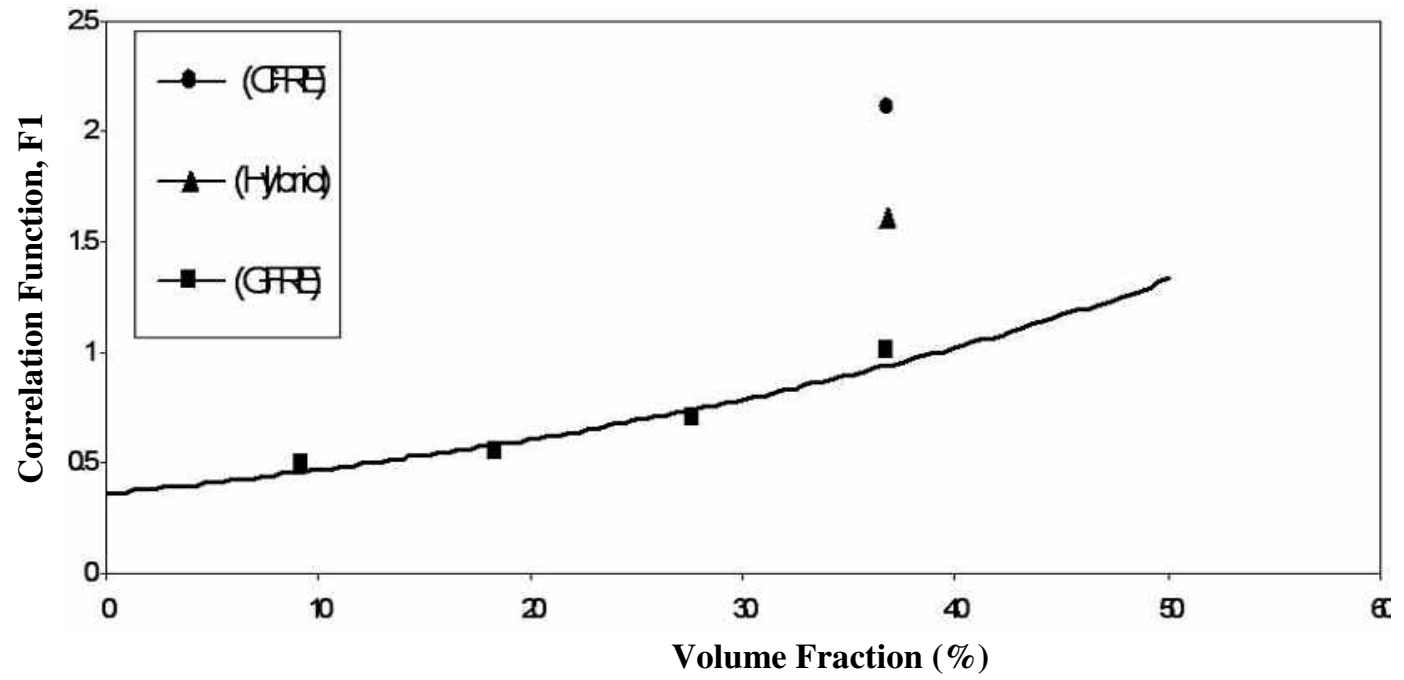

Fig. 6: Plot Of The Correlation Function $F_{1}$ Vs. Reinforcement Volume Fraction. 


\section{5-1 Application of the Suggested Modification}

1- Run few experiments to determine the variation of the elastic modulus and fracture stress with fiber volume fraction,

2- Calculate the same parameters using H-T equations,

3- Calculate $F_{1}$ according to equations (11) and (12),

4- Reduce the calculated H-T plot by $\mathrm{F}_{1}$ to match the experimental data,

5- Use extrapolation to calculate the desired parameter, i.e. $\mathrm{E}$ or $\sigma_{\mathrm{f}}$ at any volume fraction.

\section{6- CONCLUSIONS}

A mathematical analysis was conducted on the experimental results of a study conducted on epoxy-based composites reinforced by three different types of woven fabrics .

The rule of mixtures (ROM) equations and the Halpin-Tasi (H-T) equations were used in the analysis because they are the most widely used equations in the literature. The controlling parameters investigated are the elastic modulus of the composites and their fracture stress.

It was found that the ROM gives approximate values for the investigated parameters that represent upper bound values for both the elastic modulus and the fracture stress. Fracture stress values calculated according to $\mathrm{H}-\mathrm{T}$ equations showed very good correlation with the experimentally determined values. However the elastic modulus values calculated using $\mathrm{H}-\mathrm{T}$ equations showed good correlation with the experimental data for low reinforcement volume fractions. As the volume fraction increased the two values started to divert from each other considerably. A correlation function was calculated based on the differences between experimental and calculated values and was applied to the $\mathrm{H}-\mathrm{T}$ values to reduce its differences with the experimental data.

\section{REFERENCES}

[1] C.C. Chamois and G.P. Sendeckuj, J. Composite Materials , V.2, 1968, p. 332.

[2] R.M. Jones Mechanics of Composite Materials , $2^{\text {nd }}$ ed., Taylor \& Francis, USA, 1999 , p. 127

[3] S.W. Tsai , Structural Behavior of Composite Materials , NASA CR- 71 , July 1984.

[4] H.H. Daken and A.A. Ismail, Effect of carbon on the Mechanical Behavior of Carbon/Glass Woven Hybrid Composites " , $6^{\text {th }}$ ASAT conf., V.2 Cairo, Egypt , 1995 , pp 423-442

[5] J.C. Halpin and S.W. Tsai , Effects of Environmental Factors on Composite Materials , AFML-TR-67-423, June 1969.

[6] K.K. Chawla, Composite Materials Science and Engineering, Springer-Verlag, New York , 1987.

[7] J.M. Whitney, J. Structural Div. Amer. Soc. Civil Eng., 113, Jan 1973.

[8] L.E. Nielsen, Mech. Prop. of polymers and Composites, Vol. 2, Marcel Dekker, New York, 1974. 
[9] A. A. Mazen, M. Abdel Ghafaar, N. A. El-Mahallawy, "Tensile Deformation Behavior of Epoxy Composites Reinforced with Three Different Woven Fabrics", Proceedings of the Eleventh Int. Conf. on Composites Engineering, ICCE-11, 8 - 14 August 2004, South Carolina, USA.

\section{تطبيق معادلات قاعدة المخاليط وهالبين - تساى المائ \\ للمواد المركبة المصنوعة من الأيبوكسى المقوى بالألياف المنسوجة}

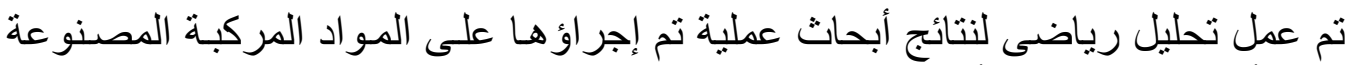
من الأيبوكسى المقوى بألياف منسوجة.

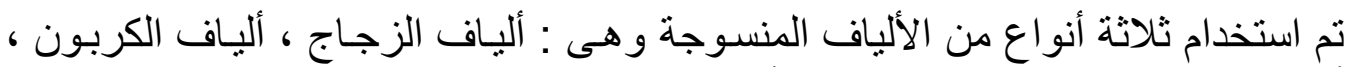

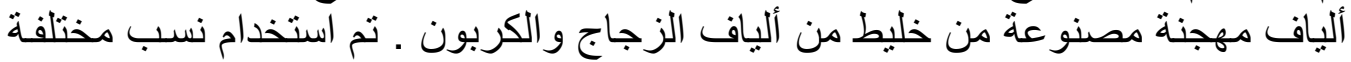

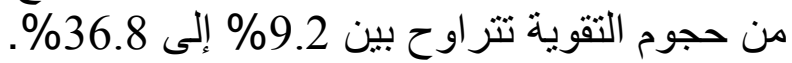

لتحليل النتائج تم حساب كل من معامل المرونة و إجهاد الكسر باستخدام معادلات قاعدة

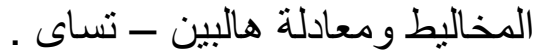

وجد أن معادلات قاعدة المخاليط تعطى نتائج تقريبية بعيدة دائما و أعلى من القيم المقاسـة

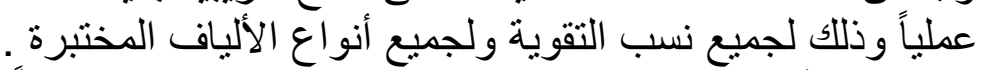

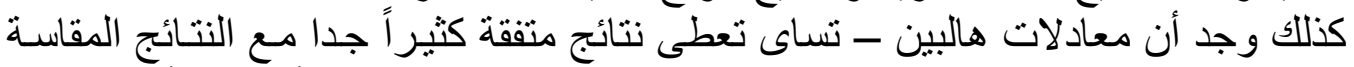

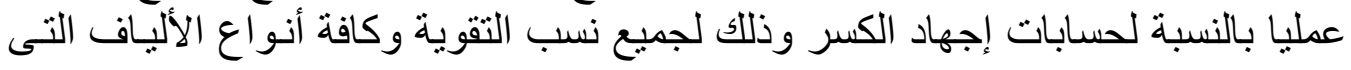
تم اختبار ها.

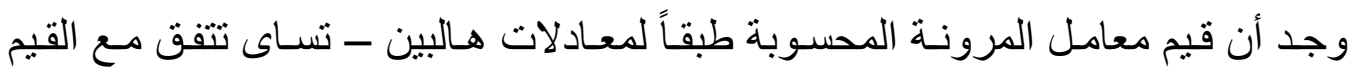

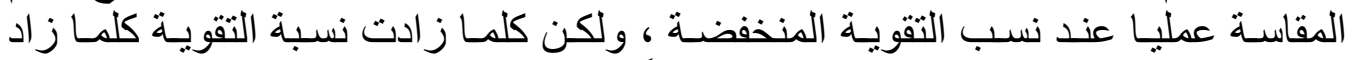
الفارق بين القيم المحسوبة والقيم المقاسة عملياً بطريقة ملحوظة ولتها

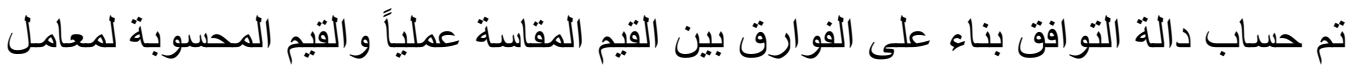
المرونة .. بتطبيق هذه الدالة يمكن إلغاء الفوارق بين الفين كلا من هذه القيم. 